\section{Acute Intestinal Obstruction due to Amoeboma}

A number of cases of intestinal obstruction were encountered in which amoebic dysentery appeared, to be the major causative agent.

Case 1.-The patient, a boy aged $3 \frac{1}{2}$, had no history of dysentery. Examination revealed the presence of a tumour in the epigastrium, and a diagnosis of intussusception was made. Laparotomy revealed an inflammatory mass the size of a billiard ball arising from the wall of the transverse colon; it was adherent to the surrounding structures and the anterior abdominal wall. There was no pus formation, and the mass was mobilized without difficulty. In view of the degree of obstruction, a Mikulicz resection was performed, with drainage of the proximal loop by means of Paul's tube. Death occurred from bronchopneumonia seven days later. The inflammatory mass was found to be a non-specific granuloma, almost certainly amoebic in origin.

Case 2.-A woman aged 54 had a palpable mass in the right hypochondrium. There was no history of dysentery. Operation showed a granulomatous mass the size of an orange arising from the proximal part of the transverse colon and presenting signs of central softening. After mobilization it was found that the intestinal lumen was only partially obliterated. The mass was therefore marsupialized through a small wound in the flank, the omentum being used as an aid in sealing it off from the peritoneal cavity. Relief of tension following aspiration of the central abscess ensured the patency of the colon. After the closure of the original paramedian wound a drainagetube was introduced into the abscess cavity. Convalescence was not complicated by the development of a faecal fistula, and resolution of the mass appeared to be complete.

\section{Acute Intestinal Obstruction due to Ileo-caecal Intussusception}

During a period of less than a year four cases of intussusception were encountered in adults. In each of these operation showed chronic inflammatory thickening of the colon suggestive of chronic amoebic dysentery. Two cases, with histories of four and seven days, were too far advanced for effective surgical treatment, and death resulted soon after admission.

Case 3.-A girl aged 14 developed severe abdominal colic while in hospital under treatment for dysentery. Rectal examination carried out twelve hours later revealed the presence of an intussusception. In view of its extent operative reduction proved to be surprisingly easy, and the bowel was found to be viable. Convalescence was uneventful.

Case 4.-A man aged 32 came with nine days' history of abdominal pain. Operation revealed an ileo-caecal intussusception which had advanced as far as the middle of the transverse colon. Complete reduction proved to be impossible and the caecum was found to be gangrenous. The proximal opening formed by the walls of the ensheathing layer was therefore closed by means of mattress sutures; the addition of interrupted sutures to anchor the entering portion of the ileum completed the procedure, by which the devitalized bowel was excluded from the peritoneal cavity. Ileotransversostomy was then performed with some difficulty owing to the friability and chronic induration of the colon. After ten days the devitalized portion of the intussusceptum was passed as slough per rectum, and further progress was uneventful.

\section{Summary}

The high carrier rate of $E$. histolytica among repatriated Service personnel is emphasized in relation to probable effects on post-war civilian practice.

Some of the surgical aspects of amoebiasis are discussed on the basis of experience gained in the treatment of African patients.

The results are given in a series of cases which include infection of the liver, perforation of the colon, acute infection of the caecum, and intestinal obstruction due to amoeboma.
My thanks are due to Mr. Arthur Copley and Mr. Algar Sweetapple for their advice and guidance in the treatment of these cases.

REFERENCES

Cropper, C. F. J. (1945). Lancet, 2, 460.

Elsdon-Dew, R. (1946). S. Afr. med. J., 20, 580.

Faust, E. C. (1930). Proc. soc. exp. Biol., N.Y., 27, 908 Morgan, C. Naunton (1944). British Medical Journal, 2, 721.

Morton, T. C. (1946). Ibid., 2, 890.

Payne, A. M. M. (1945). Lancet, 1, 206.

Rogers, L. (1922). Ibid., 1, 463.

\section{IODINE AND FAILING LACTATION}

BY

\section{MARGARET ROBINSON, M.D., D.P.H.*}

An investigation into the part played by hormones in failing lactation was started under the auspices of the Medical Research Council on the suggestion of Prof. F. G. Young, D.Sc. The work began in 1944 in St. Thomas's Hospital by permission of Mr. J. M. Wyatt and Mr. A. J. Wrigley. It was extended in 1946 to University College Hospital by permission of Prof. W. C. Nixon and Prof. F. J. Browne. During this investigation it was discovered that large doses of dried thyroid gland caused a greater increase in milk yield per day in puerperal women than any of the other hormone preparations. This led to the trial of Lugol's solution in similar cases of failure to establish lactation in the puerperium. The results from the administration of Lugol's solution were found to be even more satisfactory. It was therefore decided to publish this preliminary report.

\section{Method}

Criteria of Failure to Establish Lactation in the Puerperium.- In 500 untreated lactations in St. Thomas's Hospital the infants were test-fed each day during the puerperium, and were then followed up during the next six months. It was found that failure of lactation before the infant was 6 months old was rare where the total milk output on the fifth day of the puerperium had been at least $10 \mathrm{oz}$. $(285 \mathrm{ml}$.) and on the tenth day of the puerperium at least $16 \mathrm{oz}$. $(455 \mathrm{ml}$.). Nearly all the failures occurring in the first three months of lactation had had a total milk output either of less than $10 \mathrm{oz}$. On the fifth day of the puerperium or of less than $16 \mathrm{oz}$. on the tenth day. Therefore an output of at least $10 \mathrm{oz}$. on the fifth day of the puerperium or of at least $16 \mathrm{oz}$. on the tenth day was taken as the standard of establishment of lactation in the puerperium.

Assessment of Milk Yield.-From the fifth day of the puerperium until discharge from hospital the infants were test-fed at every feed. The sum of all the test feeds done in any one day gave the total output of milk for that day. The total output was calculated for each day of the puerperium. Owing to the fact that the patients were being discharged early from hospital on account of shortage of maternity beds, it was possible to treat only those patients who showed signs of failure on the fifth day-that is to say, those patients whose total milk yield as estimated from test feeds was then less than $10 \mathrm{oz}$. Treatment was started on the sixth day of the puerperium and continued either until the total daily milk yield had risen to $16 \mathrm{oz}$. a day or until the patient was discharged from hospital. After discharge from hospital the mothers reported with their infants when they were 4 weeks old. Owing to the shortage of beds and the distances the patients had to travel only two consecutive test feeds were

* Working with a full-time grant from the Medical Research Council at St. Thomas's Hospital, London, and at University College Hospital, London. 
possible. The times of these two test feeds were either 10 a.m. and 2 p.m. or 12 noon and 3 p.m. The average of the two test feeds was multiplied by five or by six, according to whether the infant was being fed four-hourly or three-hourly. This gave a rough estimate of the output of milk per day in the fourth week of lactation, and made it possible to compare the results from treatment with Lugol's solution with the results produced by other treatment.

Procedure.-A total of 99 cases of failure to establish lactation in the puerperium were investigated. Seventytwo were used as controls and 27 were treated with Lugol's solution. All the infants were test-fed on the fifth day of the puerperium. If, according to the criteria mentioned above, failure to establish lactation was' present on the fifth day, treatment was begun on the sixth day of the puerperium. In the case of saline injections the treatment lasted for five days. In the case of massage and treatment with Lugol's solution it lasted until the patient was' discharged from hospital or until the output of milk per day had reached $16 \mathrm{oz}$. Test-feeding started on the fifth day and continued until the patient was discharged from hospital, on the tenth or fourteenth day. The subsequent course of each lactation was followed up by two consecutive test feeds done when the infant was 4 weeks old.

Materials.-Six drops of Lugol's solution (5\% iodine in $10 \%$ aqueous potassium iodide) in milk were given by mouth twice a day. This treatment was continued until the yield of breast milk had risen to $16 \mathrm{oz}$. a day. Twentyseven cases were treated. Seven had to be discarded for the following reasons: (1) Three of the infants were premature and were not fit to be test-fed. It was found impossible to obtain an accurate estimate of the daily amount expressed. (2) Three mothers had painful nipples. Breast-feeding had to be stopped within twenty-four hours of starting treatment, as the patients refused to go on breast-feeding because of the pain. (3) One mother had had lumpy breasts, which became painful after twenty-four hours' treatment with Lugol's solution. The Lugol's solution had to be stopped, and treatment with oestrogens was begun. By the time the breasts were rendered soft and painless with the oestrogens it was too late to start treatment with Lugol's solution, because she had to be discharged on account of the shortage of maternity beds. The infant was bottle-fed.

It has been found that thickened, tender, and lumpy breasts that produce a scanty secretion of a thick fatty material are only made worse by treatment with Lugol's solution, and the amount of secretion is' not increased. If, however, the lumps and tenderness are removed by giving $5 \mathrm{mg}$. of stilboestrol four-hourly by mouth, then Lugol's solution will increase the output of milk and the lumps do not recur.

Controls.-(1) Eleven cases were given breast massage as advocated by Randall (1943). Treatment started on the sixth day and continued until the thirteenth day of the puerperium. (2) Physiological saline.-Nineteen cases were treated with intramuscular injections of $1 \mathrm{ml}$. of physiological saline. The injections were given into alternate buttocks on five consecutive days, starting on the sixth day of the puerperium. (3) No treatment.-Twenty-one cases were given no treatment. Test-feeds were done from the fifth day until the thirteenth day of the puerperium. In four of them secretion had completely ceased before the thirteenth day. (4) Normal lactation.-Twenty-one women who had no difficulty with lactation were test-fed from the fifth day of the puerperium until the thirteenth day, and then at intervals up to the sixth month of lactation. The mean output of these 21 women was calculated for each day of the puerperium.

\section{Results}

The results are set out in a table, which gives the mean total output per day in each group of patients during the puerperium and at one month after parturition. In the group that were given Lugol's solution four patients were discharged from hospital on the tenth day and two on the twelfth day. Eight have since reported when their infants were 4 weeks old. The control groups were all investigated in St. Thomas's Hospital, and were therefore not discharged until the fourteenth day of the puerperium. All the controls reported when their infants were 4 weeks old. Among the cases treated with Lugol's solution only eight have as yet reached the age of 4 weeks.

From the table it can be seen that the patients made less effort to feed their infants when they were given no treatment than when they were given either massage or daily injections of physiological saline. The increase in output is greatest in the group of patients who were given Lugol's

Table showing the mean daily milk yield

\begin{tabular}{|c|c|c|c|c|c|c|c|c|c|c|c|}
\hline & \multirow{2}{*}{$\begin{array}{c}\text { No. } \\
\text { of } \\
\text { Cases }\end{array}$} & \multicolumn{9}{|c|}{ Day of Puerperium } & \multirow{2}{*}{$\begin{array}{l}\text { At } \\
\text { Four } \\
\text { Wks. }\end{array}$} \\
\hline & & 5 th & 6th & 7 th & 8th & 9th & 10th & 11 th & 12th & 13th & \\
\hline $\begin{array}{l}\text { Massage } \\
\text { No treatment .. } \\
\text { Saline injections } \\
\text { Cugol's solution } \\
\text { Normal }\end{array}$ & $\begin{array}{l}11 \\
21 \\
19 \\
20 \\
21\end{array}$ & $\begin{array}{r}\text { oz. } \\
7 \\
4 \\
5 \\
5 \\
14\end{array}$ & $\begin{array}{c}\text { oz. } \\
9 * \\
4 \\
5 * \\
6^{*} \\
14\end{array}$ & $\begin{array}{r}\text { oz. } \\
9 \\
5 \\
6 \\
8 \\
19\end{array}$ & $\begin{array}{r}\text { oz. } \\
9 \\
6 \\
6 \\
11 \\
18\end{array}$ & $\begin{array}{r}\text { oz. } \\
9 \\
6 \\
6 \\
12 \\
18\end{array}$ & $\begin{array}{c}\text { oz. } \\
11 \\
6 \\
8 \dagger \\
15 \\
18\end{array}$ & $\begin{array}{r}\text { oz. } \\
10 \\
8 \\
8 \\
15 \\
17\end{array}$ & $\begin{array}{c}\text { oz. } \\
11 \\
8 \\
9 \\
16 \dagger \\
18\end{array}$ & $\begin{array}{c}\text { oz. } \\
8 \dagger \\
6 \\
9 \\
17 \\
18\end{array}$ & $\begin{array}{r}o z . \\
11 \\
6 \\
12 \\
21 \\
25\end{array}$ \\
\hline
\end{tabular}

- Beginning of treatment. + End of treatment.

solution. On the thirteenth day of the puerperium the mean output of the patients taking Lugol's solution was not much less than the mean output of the normally lactating women. No iodism was encountered. All but one of the infants in this group were discharged fully breast-fed.

In this one case the mother had at no time from the birth of her infant to the seventh day of her puerperium produced more than a few drops of thick yellow fluid. On the second day her breasts became thick and ropy. She was treated with oestrogens from the third day onwards. Not until the seventh day did her breasts feel soft and empty on palpation. Treatment with Lugol's solution was therefore not begun until the seventh day. On that day she produced one teaspoonful of milk, which was manually expressed; on her thirteenth day she produced $7 \mathrm{oz}$. $(200 \mathrm{ml}$.), as calculated from test feeds on that day. The infant was sent out partly breast-fed, as owing to the shortage of maternity beds it was not possible to keep the mother in longer for further treatment.

The three mothers who had premature infants too small to test feed were all discharged from hospital with more than enough breast milk to feed their infants. They had had about seven to ten days' treatment with Lugol's solution.

Treatment of Failing Lactation After End of Puerperium. -Collection of these cases for treatment with Lugol's solution has only recently begun. So far only nine patients have started treatment. $10 \mathrm{~min}$. $(0.6 \mathrm{ml}$.) of Lugol's solution was given by mouth in milk three times a day. Three of the nine infants were fully breast-fed after three .weeks' treatment. In two cases the output of milk per day failed to rise. Four patients defaulted. In the successful cases the increase in output ranged from 5 to $9 \mathrm{oz}$. (140 to $255 \mathrm{ml}$.) per day.

\section{Conclusions}

Failure to establish a satisfactory milk output in women is apparently due to two deficiencies-oestrogens and iodine. The need for oestrogens to control the milk flow through the breast is present in the first four days after labour; the need for iodine to increase the output of milk 
is present from the fourth day onwards. These deficiencies may be present singly or together. If together, the oestrogens must be given first. Until the oestrogen deficiency is cured it is often difficult to tell whether there is an iodine deficiency. Giving Lugol's solution to a case with an oestrogen deficiency untreated only aggravates the condition and does not increase the milk output. The sign of an oestrogen deficiency is lumpy breasts with a thick yellow secretion that is difficult to express. The sign of an iodine deficiency is soft empty breasts with a scanty secretion of milk. Both oestrogens and Lugol's solution are safe and easy to give. The duration of the treatment is short. The treatment does not upset either the mother or the infant.

The number of patients with older infants who have so far been treated with Lugol's solution for failure of lactation are too few for any conclusions to be drawn. However, the outlook is hopeful, as in three cases out of five in which the mothers took the Lugol's solution for three weeks the infants became fully breast-fed. The sign that the infant has become fully breast-fed is a sudden large increase in the weekly weight gain and an increase in the number of stools. The stools return to normal when the bottle-feeds are stopped.

\section{Summary}

Twenty cases of failure to establish lactation in the puerperium were treated with Lugol's solution. The mean output per day increased by $300 \%$. One-third of a small number of failures of lactation in mothers with older infants have responded to Lugol's solution.

I am indebted to the Medical Research Council for a personal grant and to Prof. F. G. Young for his help and criticism. I wish to thank the medical and nursing staffs of St. Thomas's Hospital and University College Hospital for their co-operation.

\section{REFERENCE \\ Randall, M. (1943). Training for Childbirth, p. 87. Churchill, London.}

\section{ACUTE DILATATION OF THE STOMACH BY}

\author{
B. MARKOWSKI, M.D. \\ Surgeon Commander, Polish Navy
}

Most recorded cases of acute dilatation of the stomach have appeared as post-operative or post-anaesthetic complications. Only a few authors have described acute dilatation caused by overloading of the stomach with food. Four such cases were admitted to my surgical department within a short period.

\section{Case 1}

A Russian prisoner-of-war aged 20 was admitted to hospital in February, 1942, with frostbite of the lower limbs. His general condition was very poor and he was emaciated and pale. The lungs, heart, and alimentary system showed no abnormality. There was wasting of the upper and lower timbs with bilateral partial paralysis of the radial nerve. Both feet showed moist gangrene. He had been treated by removal of the necrotic parts of both feet and by general anti-infection therapy. On Nov. 5, 1942, after having eaten a larger dinner than usual (about 1 litre of soup and ten potatoes), he complained of abdominal pain.

Condition on Examination.-Pulse rate 60 ; temperature $98.6^{\circ}$ F. $\left(37^{\circ} \mathrm{C}\right.$.). Both feet amputated but amputation stumps unhealed and considerable purulent discharge. Left thigh oedematous. Heart and lungs normal. Abdomen dis- tended, particularly the epigastrium, but not rigid; slight epigastric tenderness; liver and spleen not enlarged; on percussion areas of dullness, and on auscultation peristaltic sounds were heard. There had been no passage of flatus since the onset of symptoms three hours before. The patient vomited frequently but only small amounts. He was sleepy, apathetic, and complaining of slight abdominal pain. A diagnosis of acute dilatation of the stomach was made.

Treatment.-A stomach tube was passed, and an injection of "prostigmin," intravenous hypertonic saline, and an enema were ordered. After three hours repeated attempts to evacuate the stomach had failed. The abdominal distension was increasing and the pain was more severe. Fluid injected down the tube to dilute the stomach contents did not return. After six hours of the same treatment there was still no evacuation of stomach contents. The patient's general condition was worse, with increasing pain and much retching. The pulse rate was now 90. Some flatus had been passed, but with no reduction in the abdominal distension.

The stomach tube was then passed once more, but with the patient lying on his side with the knees bent. There was an immediate good result and emptying of the stomach proceeded rapidly. The total amount evacuated was 8 litres, which was mainly fluid but mixed with a certain amount of digested and undigested food, mostly potatoes. After this the patient felt considerable relief and went to sleep. A few hours later he awoke feeling much better; flatus was passed normally. $\mathrm{He}$ remained in hospital for a further twelve months for treatment of his legs, but during this period he had no further stomach trouble.

\section{Case 2}

An Italian prisoner-of-war aged 30 was admitted to hospital on March 17, 1944, with a diagnosis of acute appendicitis. In 1941 he had had malaria and he also gave a history of several attacks of bronchitis. For the last three and a half months he had worked very hard in a factory. As a result of this he became so exhausted that he was admitted to the sick bay for a special diet and nursing. On March 17 his diet was as follows:

7 a.m.-Half litre "ersatz" tea and 100 g. of biscuits

10 a.m.- One piece (100-150 g.) of bread and two potatoes.

12 a.m.-One and a quarter litres of turnip soup.

2 p.m.- Half litre of skimmed milk and two biscuits.

4 p.m.-About one litre of potato purée.

After eating these meals he felt slight abdominal pain and noticed some distension of the abdomen. In spite of this he had a further meal at 6.30 p.m. consisting of one litre of potato purée and about $500 \mathrm{~g}$. of bread. Almost immediately he developed severe abdominal pain and distension, with dyspnoea and difficulty in passing flatus.

Condition on Examination.-At 9 p.m. on March 17 his pulse rate was 109 . He was well-built but emaciated. Rapid shallow respirations. No vomiting, and only a small amount of flatus passed. Lips and tongue were rather dry. Lungs normal; apex beat displaced upwards. Limbs slightly oedematous.

There was marked distension, particularly in the upper abdomen, but no rigidity; some tenderness in the epigastrium. One seemed to feel the outlines of the distended stomach, but this was not definite. On percussion the abdomen was tympanitic; the liver and spleen were not obviously enlarged. Normal peristaltic sounds were heard on auscultation. A diagnosis of acute dilatation of the stomach was made.

Treatment.-The patient was placed in the lateral position with the knees bent and a stomach tube was passed. He was also given an enema, an intravenous hypertonic saline, and a subcutaneous saline. The first and second attempts at lavage failed, but after pouring in a quantity of water to dilute the stomach contents about $4 \frac{1}{2}$ litres (with potatoes, vegetables, and bread) were removed. During each of the next five washouts 1-1 $\frac{1}{2}$ litres of fluid gastric contents were evacuated together with much gas. After two enemas, within three hours of admission to hospital, the patient had a good movement of the bowel. 